\title{
Open Surgical Procedure
}

National Cancer Institute

\section{Source}

National Cancer Institute. Open Surgical Procedure. NCI Thesaurus. Code C126391.

Traditional surgery using a long incision for visualization and for the insertion of instruments. 